\title{
New Look at the Process of Reclamation of Moulding Sands
}

\author{
S.M. Dobosz ${ }^{\mathrm{a} *}$, K. Major-Gabryś ${ }^{\mathrm{a}}$, M. Hosadyna ${ }^{\mathrm{b}}$ \\ ${ }^{a}$ AGH University of Science and Technology, Faculty of Foundry Engineering, Department of Moulding Materials, Mould \\ Technology and Foundry of Non-ferrous Metals, \\ Al. Mickiewicza 30, 30-059 Kraków, Poland \\ ${ }^{\mathrm{b}}$ HÜTTENES-ALBERTUS Sp. z o.o., ul. Turystyczna 7, 20-207 Lublin, Poland \\ *Corresponding author: e-mail: dobosz@agh.edu.pl
}

Received 16.04.2012; accepted in revised form 02.07.2012

\begin{abstract}
This paper presents a new perspective on the issue of reclamation of moulding and core sands. Taking as a premise that the reclamation process must remain on the surface of grains some not separated binding materials rests, it should be chosen the proper moulding sand's composition that will be least harmful for the reclaim quality. There are two different moulding and core sands taken into examinations. The researches prove that a small correction of their compositions (hardener type) improves the quality of the received reclaims. Carried out in this article studies have shown that such an approach to the problem of reclamation of the moulding and core sands is needed and reasonable.
\end{abstract}

Keywords: Innovative foundry materials and technologies; Moulding sand; Reclaim; Ester hardener

\section{Introduction}

There are many extensive studies and publications connected to the issues of reclamation of moulding and core sands [1-11]. These works are concerned - on the one hand mainly on the methods of reclamation, reclamation equipment, the operation systems and the intensity of removing the binding materials' rests, on the other hand on assessing the effectiveness of these methods expressed by assessing the quality of the resulting reclaim. However it is obvious that in practice it is impossible to elaborate the reclamation system that will ensure a perfect clearing of grains surface to get the reclaim being appropriate for any moulding and core sand technology. That's why - rightly - it's accepted that the reclaim should be used for the same technology from which it was received. In that situation it isn't necessary to achieve a perfectly - impossible to reach in practice - cleared from binding materials rests grains. That's why now we focused on improving reclamation systems.

In our discussion we want to look at issues of reclamation from different point of view which is the ability to make a slight correction of moulding sands composition without changing their nature (organic and inorganic binders). Taking as a premise that the reclamation process must remain a part of not separated binding materials rests on the surface of grains - it should be chosen the proper moulding sand's composition that will be least harmful for the reclaim quality.

The study showed that such an approach to the reclamation issues of moulding and core sands is appropriate and justified. In the paper the authors will try to prove it on the basis of two examples. 


\section{Loose self-hardening moulding sands with hydrated sodium silicate}

Loose self-hardening moulding sands with hydrated sodium silicate - commonly called moulding sands with water glass - are mainly used in ester technology. As moulding sands with inorganic binder they are hardly reclaimed.

In foundry practice, the most frequent are loose, selfhardening moulding sand with water glass hardened with substances based on esters of acetic acid. Gradually secretive acetic acid reacts with $\mathrm{NaOH}$ with the formation of sodium acetate, which crystallises in the later stage of hardening, strengthening the $\mathrm{Si}(\mathrm{OH})_{4}$ gel with the creation of crystals $\mathrm{CH}_{3} \mathrm{COONa} \cdot 3 \mathrm{H}_{2} \mathrm{O}$.
According to data in the literature [12] and our own research, as a result of this reaction, the compound $\mathrm{CH}_{3} \mathrm{COONa} \cdot 3 \mathrm{H}_{2} \mathrm{O}$ accumulates in the process of mechanical reclamation, resulting in the decrease of moulding sand's properties. Moreover, this compound is responsible for a plastic state appearing in the case of bigger moulds or cores. Such a state can cause deformation of the moulding sand and, in unfavourable conditions, even the destruction of the moulds or cores [12-13].

The first stage of examination was to define the influence of sodium acetate on the properties of moulding sand based on reclamation sand (Figs. 1-2) [14]. The sodium acetate appears in used moulding sand and reclamation sand, when hardeners used previously contained esters of acetic acid.

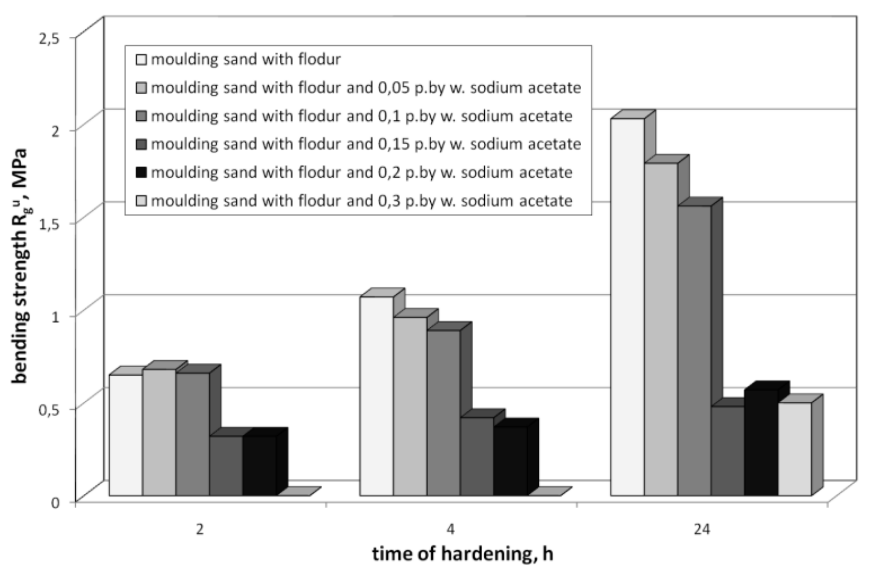

Fig. 1. The influence of sodium acetate on bending resistance of moulding sand with water glass and with flodur hardener [14]

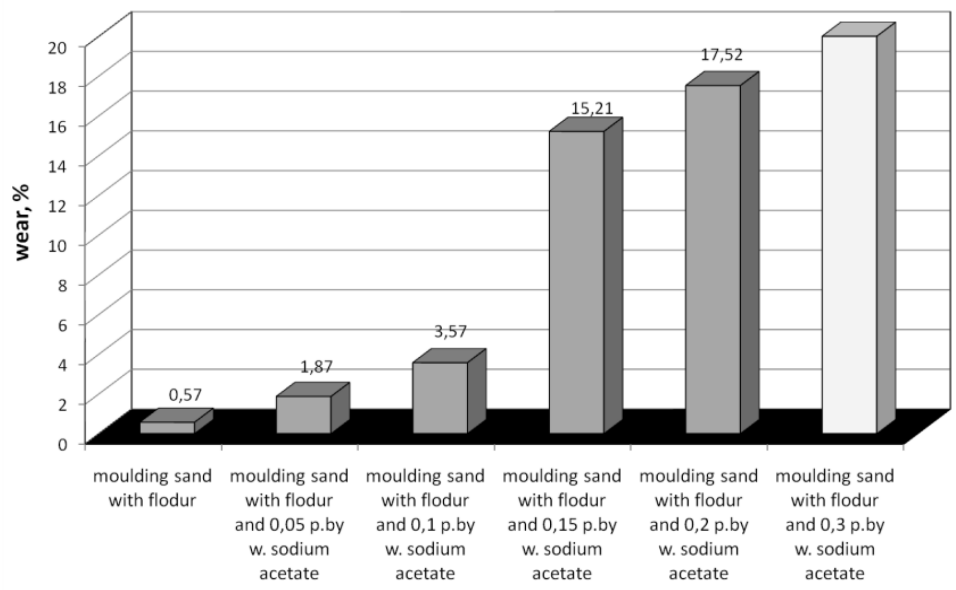

Fig. 2. The influence of sodium acetate on wear resistance of moulding sand with water glass and with flodur hardener [14]

Figures 6 and 7 show the intense negative influence of sodium acetate content on the strength and wear resistance of moulding sand containing reclamation sand and lead to the conclusion that the content of sodium acetate should not exceed $0.10 \%$. Using even a very effective system of reclamation it would be difficult to fulfil this condition. Therefore trials were carried out to develop a new generation ester hardener, based on esters of propylene carbonate: 


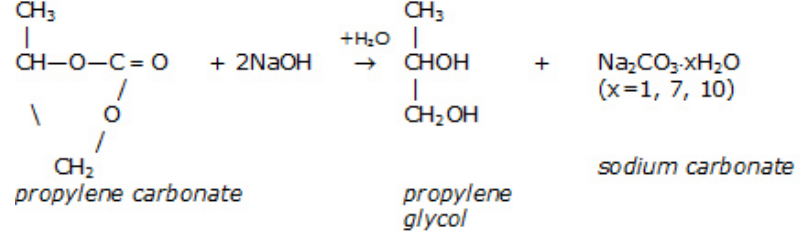

An enlarged share of sodium carbonate in reclamation sand (after dry reclamation) does not create such an unfavourable influence on the quality of reclaimed sand.

Within the frames of examination, a new hardener based on esters of carbonic acid was developed and its' influence on a wide spectrum of mechanical properties of moulding sand with water glass was determined [14]. The examinations of bending strength and curing time of moulding sand with the new hardener are presented in this paper. The new hardener is called ixional SD. The results were compared with those of moulding sand hardened with flodur hardener, based on esters of acetic acid. The new hardener confirmed its suitability for moulding sands production. It is characterized by a fast bonding of moulding sand. With the new hardener there was also developed a system of slowing agents which allows the foundry to regulate the moulding sand's life time.
The research shows that there are big possibilities of limiting the unfavourable features of moulding sand with water glass, such as bad knock-out property and low reclamation effectiveness. The new ester hardener, as a result of reaction with water glass, does not create sodium acetate, which is a cause of the poor quality of water glass moulding sand containing reclamation sand. The new hardener has been put into operation in a few Polish foundries.

\section{No-bake sands with furfuryl resin}

One of the main defect of no-bake sands with furfuryl resins apart from the high harmfulness for the environment - is a possibility of the existence of distorted graphite forms in nodular iron castings. This defect is being assigned to the diffusion of the sulphur - included in the acid hardener of this sands - to the castings surface layer [15].

Own examinations showed, that applying the moulding sand with the fresh quartz sand in the structure - even at very much diversified and high sulphur content - the occurrence of the degeneration of nodular graphite didn't appear (Fig.3) [16-17].

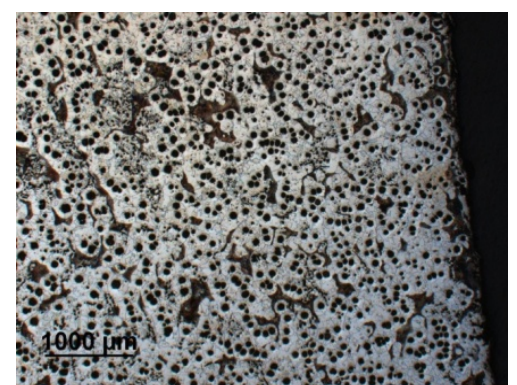

a

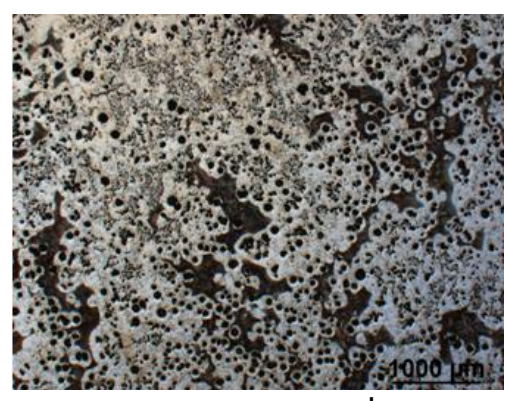

b

Fig. 3. Light photographs of the casting microstructure $\mathrm{a}-$ in the surface layer, $\mathrm{b}$ - in the interior of the casting, received in the moulding sand with the fresh quartz sand in the structure, of sulphur content $0,080 \%$ [16-17]

However in case of moulding sands based on the reclamation sand the existence of the degeneration of nodular graphite is appearing very clearly [18-19]. It is certainly dependent on the sulphur content in the moulding sand, it means in the reclamation sand and new components. This occurrence is already very much visible at the sulphur content in moulding sand of the $0.18 \%$ (Fig.4). 

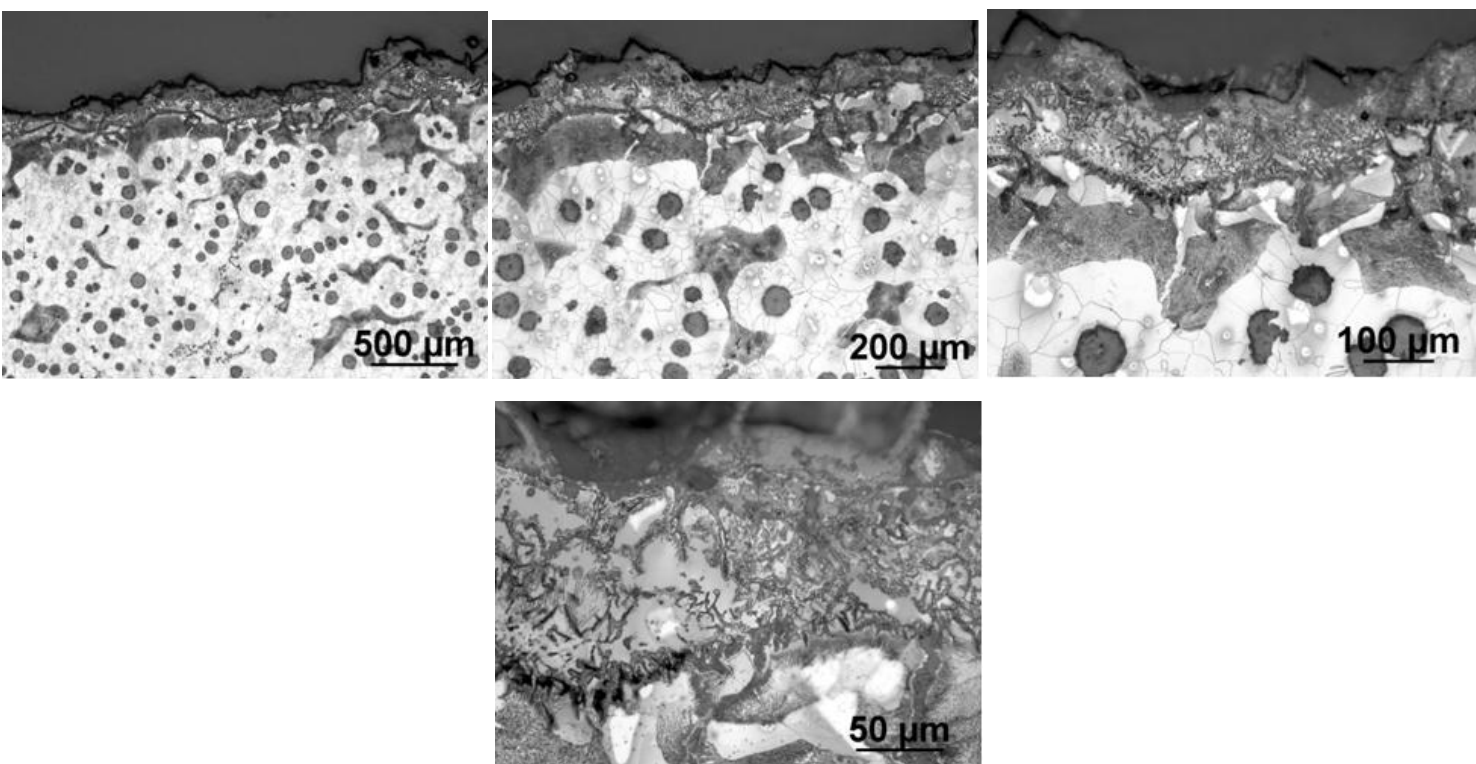

Fig. 4. Light photographs of the casting microstructure in the surface layer, received in the moulding sand with the reclamation sand in the structure, of sulphur content $0,18 \%$

Observations of the surface layer structure of experimental castings made in the no-bake mould with reclamation sand confirmed existence of the lamellar graphite in the surface layer of the nodular iron casting. The outer layer with the changed structure for casting drawn up in the moulding sand of sulphur content $0,18 \%$ was uneven, and its thickness was changing from 200 to $600 \mu \mathrm{m}$. A great coarseness of the surface area was being observed. On the border of outer layer were being remarked, in some areas, emissions of fat, extended graphite, which are well visible in Figure 4. Similar results were achieved for a sample taken from the experimental casting made in the moulding sand of sulphur content $0,22 \%$. Here also the thickness of the outer layer with the changed structure was uneven from 200 to $600 \mu \mathrm{m}$. A great coarseness of the surface area was being observed as well. On received photographs were stated the lamellar graphite in ferrite matrix in the surface layer structure, in comparing to the interior, in which graphite was found in a spheroid form in ferritepearlite matrix. Also emissions of the fat, extended graphite were visible.
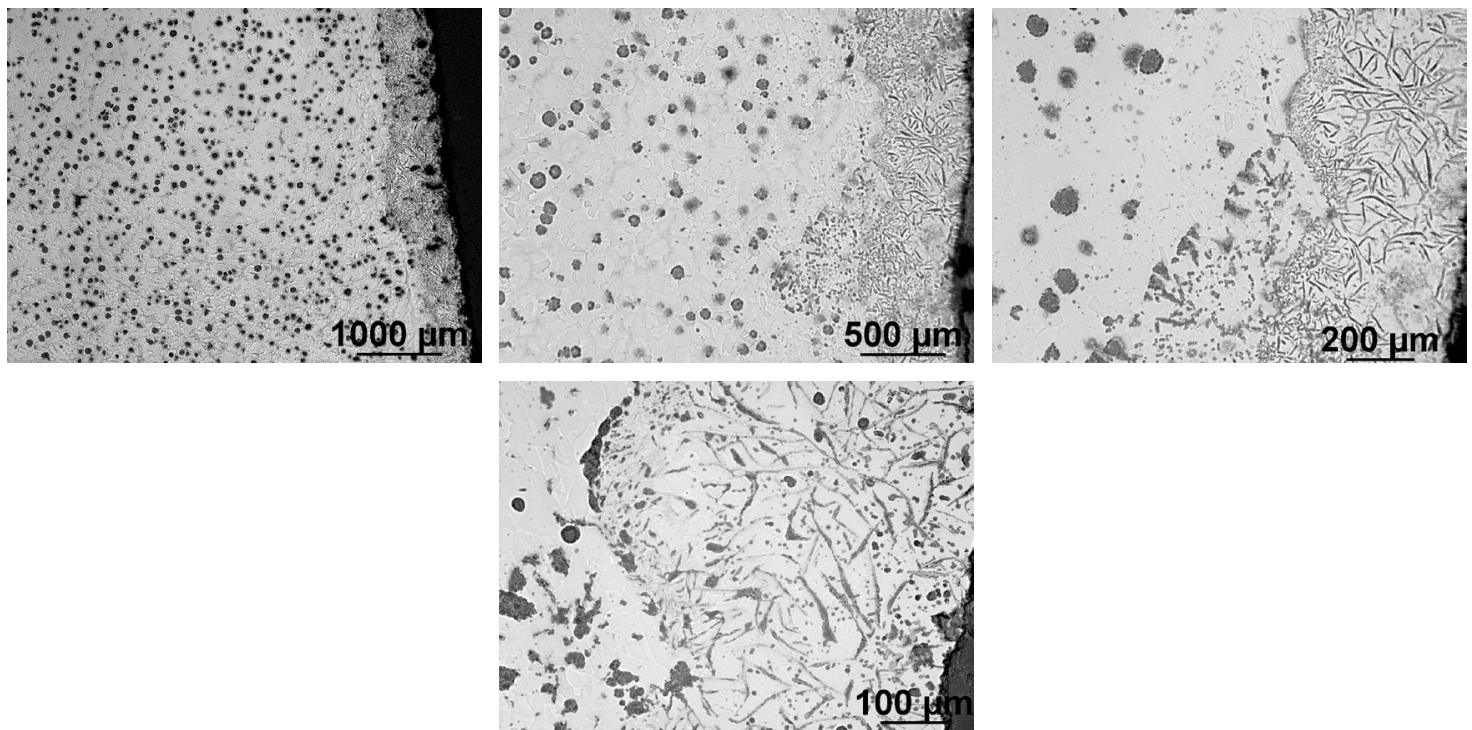

Fig. 5. Light photographs of the casting microstructure in the surface layer, received in the moulding sand with the reclamation sand in the structure, of sulphur content $0,30 \%$ 
Compared with earlier discussed castings made in the mould with the reclamation sand, sample carried out in the moulding sand of sulphur content $0,30 \%$ is characterized the even area of the lamellar graphite, which thickness take about $600 \mu \mathrm{m}$. Light photographs on the Figure 5 are presenting the structure of this casting. In outer layer, apart from the flake graphite in the ferrite matrix, it was observed spheroid graphite in different size, and the irregular shape grey emissions. Analysis of the chemical composition showed, that this irregular emissions are different oxides and sulphides which was presented on spectrograms on the Figure 6. In this experimental casting sample mainly sulphides of the manganese occur. From conducted observations result that these sulphides are placed on the end of petals of graphite, which is showed on Figure 6.

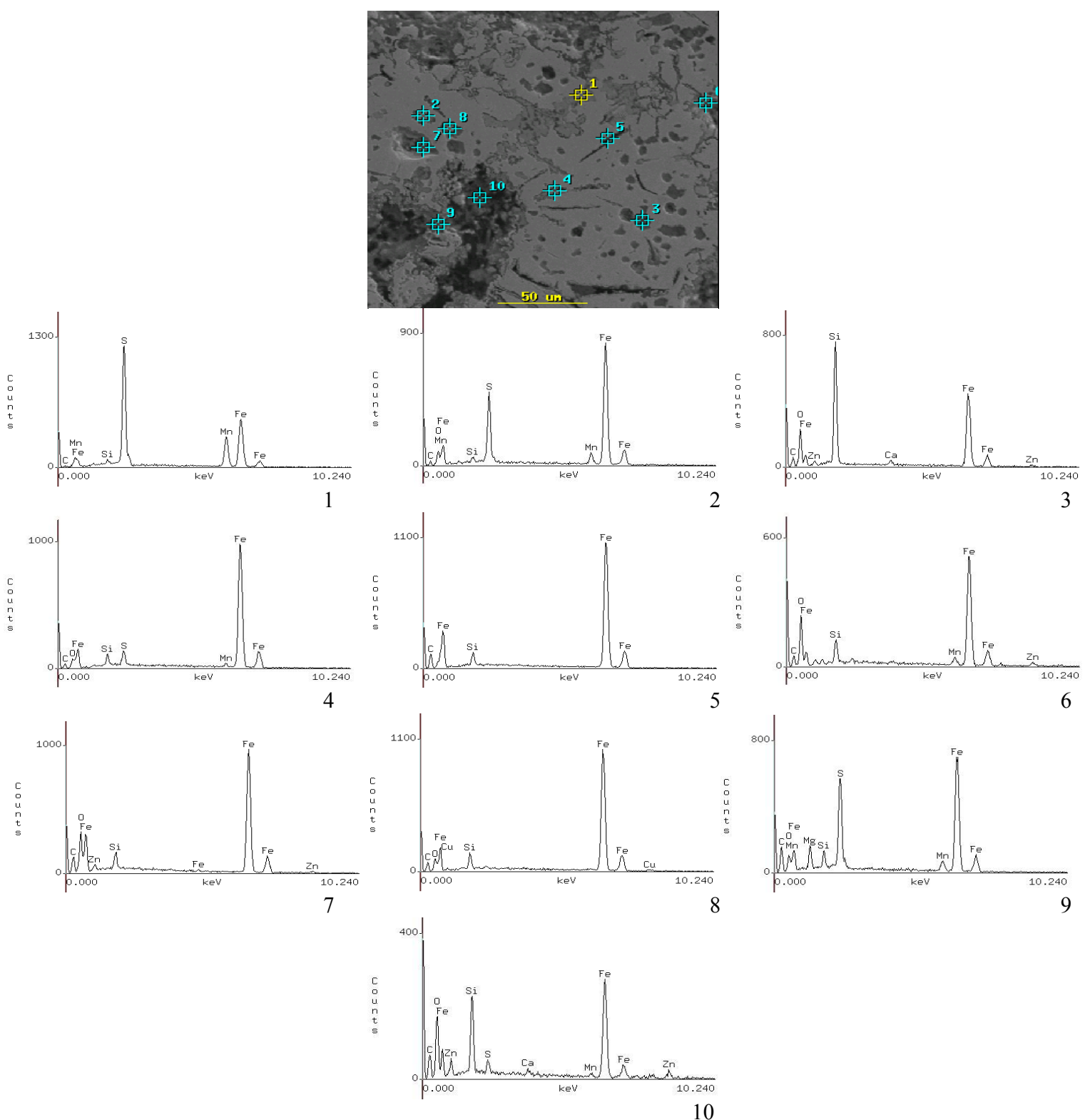

Fig. 6. SEM image of the surface layer of the casting sample with marked points, in which analysis of the chemical composition was made. Below EDS spectrograms 1-10

As a part of further activities new hardeners with the reduced sulphur content were drawn up. It will contribute to the decrease of sulphur content in the reclamation sand - irrespective of the kind and intensity of the reclamation process - what will let for restricting the degeneration of spheroid graphite in the nodular iron castings. 


\section{Conclusions}

The examples of own research convinced the effectiveness of actions taken to improve the quality of reclaims from loose selfhardening moulding sands. These activities were, firstly, to assess the effect of the binding materials residue left on the reclaim grain surface on its quality and, secondly, to take action to make these inevitably - residues not decreasing the quality of moulding sand. The actions taken in the paper were to change the hardeners. The researches have shown that such efforts are effective and can affect a significant improvement in the efficiency of the reclamation process.

\section{Acknowledgements}

The study was financed by resources allocated for science in years 2010-2013 as the Research Project No. N N507 583938

\section{References}

[1] Dańko, J., Dańko, R. \& Łucarz, M. (2007). Processes and Equipment for used sand reclamation (in Polish) (pp. 285291), Scientific Edition “Akapit”, ISBN 978-83-89541-88-8

[2] Maniowski, Z., Pezarski, F. \& Izdebska-Szanda, I. (1990). Author help in implementation of mechanical sand reclamation process of self-hardening moulding sands based on water-glass with a disc reclamation device in $\mathrm{ZM}$ „POMET”-Poznan Foundries (in Polish), Transactions of the Foundry Research Institute Krakow, 7-25. ISSN 1899-2439.

[3] Wheeler, R. (1997). A solution to enable the thermal reclamation of alkaline phenolic ester Bondem sands, Foundryman 90(7), 255-257.

[4] Spillner, A. (1998). Successful pilot project for the reclamation of used sand from water glass in aluminum foundries (in German), Giesserei-Prax. 9, 366-368.

[5] Łucarz, M., Dańko, J., Ludwin, S. \& others (2002). Patent RP P-317782. Poland. Reclamation segment of centrifugal device (in Polish).

[6] Łucarz, M. (1998). Analysis of the impact of centrifugal reclamation device construction on effects of its work (in Polish). In $12^{\text {th }}$ Reporting Conference Metallurgy 98, 23-26 September 1998 (pp. 205-210), Krynica, Poland.

[7] Polzin, H. (1999). The reclamation of moulding sands with water glass in several rounds (in German), Giesserei-Prax. 3, 101-105.
[8] Dańko, J. \& Lewandowski, J.L. (1999). Reclamation of selfhardening moulding sand with water glass (in Polish), Foundry Revision 3, 91-93.

[9] Pezarski, F., Smoluchowska, E., Maniowski, Z., Izdebska-Szanda, I. \& Bogacz, T.(2000). Sands reclamation research of self-hardening mouldig sands mixed with sodium silicate and an alkali resole resin (in Polish), Solidification of Metals and Alloys 2(43), 427-433.

[10] Pezarski, F, Izdebska-Szanda, I. \& Maniowski Z. (2003). Research of sands from used foundry moulding sands according to the vibration method (in Polish), Materialove inzinierstvo 10(3), 275-278.

[11] Fan Zitian, Huang Naiyu, Wang Huafang, Dong Xuanpu (2005). Dry reusing and wet reclaiming of used sodium silicate sand, China Foundry (1), 38-43.

[12] Jelinek, P. (2004). Binding systems of foundry moulding sands (in Czech), OFTIS Ostrava. ISBN 80-239-2188-6

[13] Major-Gabryś, K. (2007). Moulding sands with water glass having increased knock-out properties (in Polish). Unpublished doctoral dissertation, AGH-University of Science and technology, Krakow.

[14] Major-Gabryś, K. \& Dobosz, S.M. (2010). Loose selfhardening moulding sands with hydrated sodium silicate and liquid ester hardeners (in Polish). In Committee of Metallurgy of Polish Academy of Sciences, Polish Metallurgy in 2006-2010 (pp. 328-335). Krakow, Scientific Edition "Akapit".

[15] Hosadyna, M., Dobosz, S.M. \& Jelinek, P. (2009). The diffusion of sulphur from moulding sand to cast and methods of its elimination, Archives of Foundry Engineering 9(4), 73-76. ISSN 1897-3310.

[16] Dobosz, S.M. \& Hosadyna, M. (2010). The new hardeners for self-hardened moulding sands having lower sulphur emission (In Polish). In $2^{\text {nd }}$ Conference: Moulding and core Materials, 29-31 August 2010 (pp. 1-20), Kazimierz Dolny, Poland.

[17] Hosadyna, M., Dobosz, S.M. \& Major-Gabryś, K. (2011). Influence of the type of the hardener on the sulphur diffusion of moulding sand to the casting surface. Archives of Foundry Engineering 11(spec. Iss. 2), 87-92. ISSN 1897-3310.

[18] Hosadyna, M., Dobosz, S.M. \& Kusiński, J. (2011). Quality of the reclamation sand and casting surface structure. Archives of Foundry Engineering 11(1), 39-42. ISSN 18973310 .

[19] Hosadyna, M., Dobosz, S.M. \& Kusiński, J. (2012). Influence of over-coolong the nodular cast iron to the graphite form in the surface layer. Archives of Foundry Engineering 12(1), 43-46. ISSN 1897-3310. 